Discussion Paper Series A No.684

On the Ricardian Invariable Measure of Value in General Convex Economies

\author{
Kazuhiro Kurose \\ (Graduate School of Economics and Management, \\ Tohoku University) \\ and \\ Naoki Yoshihara \\ (Department of Economics, University of Massachusetts Amherst, \\ Institute of Economic Research, Hitotsubashi University and \\ School of Management, Kochi University of Technology)
}

October 2018

Institute of Economic Research

Hitotsubashi University

Kunitachi, Tokyo, 186-8603 Japan 


\title{
On the Ricardian invariable measure of value in general convex economies*
}

\author{
Kazuhiro Kurose ${ }^{\dagger}$ and Naoki Yoshihara
}

September 22, 2018

\begin{abstract}
This study examines the possibility of an invariable measure of value when price changes induced by income redistribution between profit and wages take place in general convex economies. While Ricardo searched for an invariable measure of value with respect to changes in both the factor income distribution and the technique, Sraffa constructed a standard commodity serving as a measure of the change in a factor income distribution alone by leaving aside the possibility of changes in the size and composition of output and means of production. This study allows for the possibility that a change in factor income distribution involves a change in technique, and proposes an extension of Sraffa's standard commodity. Then, we show that it serves as an invariable measure of value with respect to the income redistribution, even though it involves a change in technique. Finally, we examine whether the linear distributional relation is preserved.
\end{abstract}

Keywords: Ricardo's invariable measure of value, Sraffa's standard commodity, Linear relation of factor income distribution, General convex economies

JEL Classifications: B51, D33, D51

${ }^{*}$ The authors record their special thanks to the managing editor Robert Scazzieri and the three referees for their detailed comments that improved the paper substantially. This paper was written when the first author was a visiting fellow of the Catholic University of Milan from 2012 to 2013. He wishes to express his gratitude to the university. An earlier version of this paper was presented at the 17th ESHET conference, the Japanese Society for Post Keynesian Economics, Japan Society of Political Economy, and seminars in Milan, Sendai, and Tokyo. The authors thank all the participants, especially Enrico Bellino, Amitava Dutt, Luigi Pasinetti, Roberto Veneziani, Peter Skott, Soon Ryoo, Gil Skillman, Neri Salvadori, and Bertram Schefold for their helpful comments and suggestions. The first author gratefully acknowledges financial support from JSPS KAKENHI (17K03615) and the Nomura Foundation. The usual disclaimer applies.

${ }^{\dagger}$ Graduate School of Economics and Management, Tohoku University, Kawauchi 27-1, Aobaku, Sendai 980-8576, Japan. E-mail: kazuhirokurose@tohoku.ac.jp

${ }^{\ddagger}$ Department of Economics, University of Massachusetts Amherst, Crotty Hall, 412 North Pleasant Street, Amherst, MA 01002, USA; The Institute of Economic Research, Hitotsubashi University, Naka 2-1, Kunitachi, Tokyo 186-8603, Japan; and School of Management, Kochi University of Technology, Tosayamada, Kami-city, Kochi 782-8502, Japan. E-mail: nyoshihara@econs.umass.edu 


\section{Introduction}

As is well known, Ricardo (1951A) defined an invariable measure of value as a measure whose value is invariable with respect to changes in both the factor income distribution and the technique. ${ }^{1}$ When commodities vary in terms of their relative value, we cannot, in general, ascertain which of them fell and which rose in real terms, because the value of the medium in which prices are expressed may also vary, which affects the variation of relative prices. For instance, although Ricardo (1951A, p. 45) believed that a change in technique had a greater impact on relative prices than did a change in the factor income distribution, he was perplexed by even the latter change: the value of net output may vary due solely to a change in the value of the medium caused by a change in the distribution of the net output between profits and wages. This problem can still occur today, and is quite important in economic theory. When stating the economic principles that regulate exchangeable value and price, we should distinguish carefully between variations that belong to the commodity itself, and those occasioned by a variation in the medium (Ricardo, 1951A, p. 48). Indeed, investigating the effect on the variation of relative commodity prices of a change in the factor income distribution, distinguished from the variation in the medium, would be an important process for the analysis of the economic welfare corresponding to the consumption of those commodities. In this respect, an invariable measure of value would play a significant role, if it exists: we could ascertain which commodities rise and fall in real value when relative prices vary by comparing them in turn with such a medium (Ricardo, 1951A, p. 43).

Unfortunately, Ricardo failed to find a commodity that serves perfectly as an invariable measure of value. However, he asserted that gold as money is a commodity that possesses as near an approximation to an invariable measure of value as can be theoretically conceived (Ricardo, 1951A, p. 45). According to Roncaglia (2009), Ricardo's failure is attributable to the following two reasons. The first is that he attempted to identify a single commodity as an invariable measure of value. This can occur in economies with multiple commodities only if the economies have several trivial features; for example, there is only one basic commodity in the sense of Sraffa (1960, p. 8), or the so-called organic composition of capital is identical among all sectors. The second reason is that he attempted to resolve the two distinct causes (i.e. a change in technique and in the factor income distribution) of variations in the value of the medium simultaneously. According to Harcourt (2003, p. 128), Ricardo's search for a measure of value invariant to changes in both factor income distribution and technique is $a$ will-o'-the wisp.

In order to overcome the impasse into which Ricardo plunged, Sraffa (1960) divided the problem of identifying the invariable measure of value into two parts. One part of the problem is to search for a measure of value that is invariable with respect to a change in technique,

\footnotetext{
${ }^{1}$ Ricardo's concern about an invariable measure of value appeared as early as his contributions to the "bullionist" controversy. As a bullionist, he wrote notes on the stability of the general price level during the Napoleonic wars, which are collected in Ricardo (1951B). He had already pointed out the need for an invariable measure of value, which would enable an intertemporal comparison of values, and argued that such a measure did not exist in reality, although money could be regarded as an invariable measure of value, at least as a first approximation (see Ricardo, 1951B, p. 65). However, his arguments at this stage were not rigorously based on the theory of value. See Kurz and Salvadori (1993, 2015) and Sraffa (1951) for discussions of the conceptual transition of Ricardo's invariable measure of value.
} 
leaving aside the possibility of a change in the factor income distribution. The other part is to search for a measure of value that is invariable with respect to a change in the factor income distribution, leaving aside the possibility of a change in technique. Sraffa concentrated exclusively on the latter case by constructing a special, composite commodity, termed a standard commodity. ${ }^{2}$ As we will see, he also demonstrated that the linear distributional relation between profit and wages holds if the standard commodity is adopted as the numéraire.

Sraffa (1960, p. v) considered a situation in which there are no changes in output or proportions where different means of production are used by an industry. He argued that constant returns to scale is not therefore assumed, but that there is no harm in assuming it to be a "temporary working hypothesis." In contrast, neoclassical economists, such as Burmeister (1968, 1975, 1977, 1980, 1984), Samuelson (1987, 1990, 2000), Samuelson and Etula (2006), and Solow (2014), asserted that constant returns to scale should be explicitly assumed; otherwise, the relevance of the standard commodity and the linear distributional relation is lost. According to them, the Sraffian analysis becomes invalid without assuming constant returns to scale if the size and composition of output change.

In the next section, we discuss the debate on the assumption of constant returns to scale between Sraffian and neoclassical economists in relation to the invariable measure of value. However, our main concern does not lie in the debate itself. Rather, we focus on the fact that the Ricardian problem on the invariable measure of value has, thus far, only been partially solved. As already mentioned, Sraffa's standard commodity cannot serve as an invariable measure of value unless the possibility of a change in technique is left aside. The abovementioned debate is relevant in this respect because, under constant returns to scale, while fixing a factor income distribution, a change in technique cannot occur due to a change in the size and composition of output. ${ }^{3}$ However, even under constant returns to scale, the cost-minimizing technique may vary as a result of a change in the factor income distribution whenever multiple alternative techniques are available. ${ }^{4}$

Thus, the main objective of this study is to solve the Ricardian problem of an invariable measure of value when a change in the factor income distribution may involve a change in the cost-minimizing technique. We discuss this problem in the context of an economy with a convex production possibility set. Such a general model of production is suited to our subject because it can represent the case of multiple alternative techniques being available in the technical choice problem at a given moment in time. Moreover, in such a general model of an economy, we can examine any possible interdependence among changes in the aggregate demand functions of commodities, size and composition of output produced, factor income

\footnotetext{
${ }^{2}$ In contrast to Sraffa's solution, Pasinetti's $(1981,1993)$ dynamic standard commodity is a measure of value invariant to technical progress, leaving aside the possibility of a change in the factor income distribution, when the labor productivity of the overall economic system has always improved over time. In other words, the dynamic standard commodity is a measure of value that always requires the same quantity of "augmented" labor over time.

${ }^{3}$ The non-substitution theorem ensures this property. See, for example, Morishima (1964, pp. 68-69).

${ }^{4}$ Both schools have recognized this feature, because they discussed the changing pattern of the costminimizing technique corresponding to a change in the factor income distribution in detail during the period of the Cambridge capital controversies. Indeed, even Garegnani (1984), a Sraffian economist, indicated there is an indirect effect of the factor income distribution on the choice of technique, although he argued that the indirect effect is not the core of classical economic analyses.
} 
distribution, and cost-minimizing technique.

We first propose a generalization of the standard commodity in such a general convex economy, and then examine whether it can serve as an invariable measure of value with respect to a change in the factor income distribution. In this context, we generalize the definition of the price invariance of a measure of value proposed by Baldone (2006) for the case of general convex economies. The generalized standard commodity is shown to serve as an invariable measure of value, even if the change in the factor income distribution implies a change in the cost-minimizing technique. Thus, applying the generalized standard commodity as the numéraire, it can be ascertained how the relative prices of commodities are affected by a change in the factor income distribution and its associated change of techniques. Moreover, we examine whether the linear distributional relation holds for the generalized standard commodity.

The remainder of the paper is organized as follows. In Section 2, we review the notion of the price invariance of a measure of value, as defined by Baldone (2006), and argue the role of the standard commodity in relation to the Ricardian invariable measure of value. Subsequently, we refer to several critiques that neoclassical economists gave to Sraffa (1960), especially concerning the relationship between the assumption of constant returns to scale and the relevance of the standard commodity. In order to deal with Ricardo's original supposition that the possibility of changes in both the factor income distribution and technique is allowed, in Section 3, we generalize the concept of the standard commodity. Moreover, we demonstrate that the standard commodity serves as an invariable measure of value in general convex economies, and show the condition for the linear distributional relation. In Section 4, we present our concluding remarks.

\section{Ricardian Invariable Measure of Value and Sraffian Standard Commodity}

First, we review the meaning of the "price invariance" of a measure of value, because there is some debate on this issue. ${ }^{5}$

As already mentioned, Sraffa (1960) separated the Ricardian problem on the invariable measure of value into two parts, and then searched exclusively for the measure, the value of which is invariable with respect to a change in the factor income distribution, leaving aside the possibility of a change in the cost-minimizing technique. He formulated the price system in the case of no joint production as follows:

$$
p=(1+\pi) p A+w L,
$$

where $p, L \in \mathbb{R}_{+}^{n}, \pi, w \in \mathbb{R}_{+}$are vectors of prices, labor coefficients, the rate of profit, and the wage rate, respectively. The physical input coefficient matrix $A \in \mathbb{R}^{n \times n}$ is assumed to be productive and, for the sake of simplicity, indecomposable.

\footnotetext{
${ }^{5}$ See, for example, Baldone (2006), Bellino (2004), Flaschel (1986), Schefold (1989; 1997, chap, 4), and Woods (1990) with respect to the debate.
} 
Price system (1) is a system of $n$ equations in $n+2$ unknowns, and thus there are several ways to close the system, usually by exogenizing either $\pi$ or $w$ and choosing an arbitrary commodity (or a commodity bundle) as the numéraire. However, according to Baldone (2006), this is not an appropriate way to analyze the invariable measure of value. Indeed, when an arbitrary commodity bundle is chosen as the numéraire, we cannot investigate the effect of a change in the factor income distribution on the price of the numéraire, because it is assumed to be constant, by definition. The value of an invariable measure must be constant, irrespective of whether it is selected as the numéraire or not. In order to examine the properties of an invariable measure of value, he argued that both the rate of profit and the wage rate must be fixed without using any commodity numéraire. For a fixed wage rate $w$, needless to say, the rate of profit must be fixed in the range of $\pi \in[0, \Pi]$, where $\Pi$ is the maximum rate of profit; otherwise, the prices do not remain positive.

Then, let us fix the rate of profit and the wage rate in monetary terms so as to keep prices positive. ${ }^{6}$ Let $b \in \mathbb{R}_{+}^{n}$ be a commodity bundle. From (1), the price of $b$ is expressed as follows:

$$
p b=(1+\pi) p A b+w,
$$

where we adopt a normalization of $L b=1$. Note that the price of $b$ is determined because both the rate of profit and the wage rate are fixed at specific rates. Therefore, as mentioned in footnote $6,(2)$ represents the absolute prices. In general, the changes in the rate of profit $(\Delta \pi)$ and in the wage rate $(\Delta w)$ cause the price of $b$ to vary, as follows:

$$
\Delta p b=(1+\pi+\Delta \pi) \Delta p A b+\Delta \pi p A b+\Delta w .
$$

Indeed, when the factor income distribution changes, $\Delta \pi \neq 0 \neq \Delta w$. Moreover, in general, it follows that $\Delta p b \neq 0$, even though the change in the factor income distribution implies the following income redistribution between profit and wage:

$$
\Delta \pi p A b+\Delta w=0
$$

where the change in profit is just counterbalanced by the corresponding change in wages at the initial prices. If $\Delta p b \neq 0$ holds, this implies that the commodity bundle $b$ (or its net product $(I-A) b$ ) cannot serve as an invariable measure of value and, thus, cannot isolate the price movements of any other commodity bundles. Moreover, (4) no longer holds at the new prices. In this case, commodity bundle $b$ is termed a variable measure of value.

Supposing that the value of physical inputs required to produce $b$ and the value of $b$ are proportional, for example, at a rate of $\theta$, irrespective of the levels of $\pi$ and $w$, we have

$$
\frac{p A b}{p b}=\theta
$$

\footnotetext{
${ }^{6}$ Baldone (2006) defined absolute prices as nominal prices, where the rate of profit and wage rate are fixed in monetary terms. Furthermore, he argued that

"investigating the properties of absolute prices in order to select a "correct" numéraire is an a priori that must precede a relative price analysis."
} 
From (5), (2) can be rewritten as follows:

$$
p b=(1+\pi) \theta p b+w .
$$

Since (5) implies that the physical inputs necessary to produce $b$ have the same physical composition as $b$, we can treat $b$ as if it consists of a single and homogeneous commodity. Thus, we can show that in the production of $b$, satisfying (5), the change in profit caused by the change in the rate of profit can always be counterbalanced by the opposite change in wages, without causing a change in the price of $b$. This implies price invariance for commodity bundle $b$ with respect to a change in the factor income distribution.

In order to clarify the above point, we follow a similar procedure to that used in (3), as follows:

$$
\Delta p b=(1+\pi+\Delta \pi) \theta \Delta p b+\Delta \pi \theta p b+\Delta w .
$$

This implies that for $\pi+\Delta \pi \neq(1-\theta) / \theta$, we have:

$$
\Delta p b=[1-(1+\pi+\Delta \pi) \theta]^{-1}(\Delta \pi \theta p b+\Delta w) .
$$

Thus, by (5) and (7), $\Delta p b=0$ holds if and only if $\Delta \pi p A b+\Delta w=\Delta \pi \theta p b+\Delta w=0$. That is, (4) implies the price invariance of a commodity bundle satisfying (5), and vice versa. Moreover, from (3), we obtain $\Delta p A b=0$ whenever $\Delta p b=0$ holds.

The above argument suggests that if a commodity bundle satisfying (5) exists, its price is invariable with respect to a change in the factor income distribution. Therefore, such a commodity bundle serves as an invariable measure of value. Moreover, this is simply Sraffa's (1960) standard commodity, which is obtained by the following system of equations:

$$
\left\{\begin{aligned}
A b & =\lambda b \\
L b & =1
\end{aligned}\right.
$$

Of course, $\theta$ is the maximum of $\lambda$ : it is the Frobenius eigenvalue of $A$. Mathematically, the standard commodity $b$ is the eigenvector corresponding to the Frobenius eigenvalue of $A$. The Perron-Frobenius theorem ensures that $\theta>0$ and $b>\mathbf{0}$, because matrix $A$ is assumed to be indecomposable. Moreover, it is well known that $\theta \equiv \frac{1}{1+\Pi}$ holds, where $\Pi$, termed the standard ratio, is the maximum rate of profit obtainable by $A$. Sraffa (1960) refers to (8) as the standard system.

Furthermore, with regard to the invariable measure of value, Bellino (2004) notes two effects of a change in the factor income distribution on relative prices when a commodity numéraire is adopted: the own-industry effect and the numéraire effect. Suppose that the relative prices are unchanged when the factor income distribution changes. Recall that, as (1) shows, the equilibrium prices are exactly the same as the sum of the cost of labor and the means of production. Now, suppose that the wage rate decreases, and the rate of profit increases, assuming that prices are kept constant. ${ }^{7}$ Therefore, the cost of labor decreases and the cost of the means of production increases in all industries. The reduction of the cost

\footnotetext{
${ }^{7}$ Here, we do not need to assume the rate of profit corresponding to the reduced wage rate. We need only to obtain uniform rates of wage and profit in all industries at this stage.
} 
of labor depends on the labor coefficient of the industry, while the increase in the cost of the means of production depends on the aggregate value of the means of production, which depends on the input coefficients in the industry. Unless the proportion of labor to the means of production is uniform in all industries, the reduction of the cost of labor does not in general match the increase in the cost of the means of production among industries; the reduction would be less than the increase at a uniform rate of profit in industries with a sufficiently low proportion of labor to the means of production, so those industries would have a deficit. The reduction would be more than the increase at a uniform rate of profit in industries with a sufficiently high proportion of labor to the means of production, so those industries would have a surplus. Then, Sraffa argues that the change in relative prices is required in order to eliminate all surpluses and deficits generated by the change in the factor income distribution under the assumption that the relative prices are kept constant. He subsequently asserts that there would be a 'critical' proportion of labor to the means of production, which marks the watershed between deficit and surplus industries, and the price of the commodity produced by the industry with such a 'critical' proportion does not need to change when the factor income distribution changes. This is because the reduction in the cost of labor is always equal to the increase in the cost of the means of production, just as in the cases where the proportion of labor to the means of production is uniform among all industries or there is only one basic good in an economy. Therefore, unless the numéraire industry has such a 'critical' proportion, the value of the numéraire is not constant. As already mentioned, such a numéraire is a variable measure of value.

This demonstrates that the change in the factor income distribution has two effects on the change in relative prices; one is that the variation in the price of a commodity arises from the necessity to eliminate the surplus or deficit in the corresponding industry, which is the own-industry effect; and the other is that the variation in the price of a commodity arises from the necessity to eliminate the surplus or deficit in the numéraire industry, which is the numéraire effect. Thus, when the invariable measure of value is adopted as the numéraire, the numéraire effect must be absent, by definition.

When the standard commodity $b$ is adopted as the numéraire of the price system (or, more precisely, the net product of $b$ satisfying (5) is adopted as the numéraire; i.e. $p[I-A] b=1$ ), we obtain $\pi p A b+w=1$ from (2). Since $p A b=1 / \Pi$, we obtain:

$$
\pi / \Pi+w=1 .
$$

When the standard commodity is adopted as the numéraire of the price system, the term $p$ disappears in the price equation of the numéraire. This is because, as already mentioned, the physical inputs required to produce $b$ have the same physical composition as $b$ itself. When the factor income distribution changes, we obtain from (9):

$$
-\Pi \Delta w=\Delta \pi .
$$

This is the condition for the absence of the numéraire effect shown by Bellino (2004). Note that it also indicates that the income redistribution represented by (4) takes place. In other words, if the absolute price of a commodity (bundle) is invariable with respect to a change in 
the factor income distribution, it satisfies Bellino's condition for the absence of the numéraire effect.

It is also well known that we obtain a linear distributional relation from (9) if the standard commodity is adopted as the numéraire of the price system:

$$
\pi=\Pi(1-\omega),
$$

where $\omega \equiv \frac{w}{p[I-A] b}$. Then, (10) means that once the wage share/rate in terms of the standard commodity is known, we can obtain the rate of profit without referring to the price system. This implies a possibility of treating the factor income distribution independently of commodity prices (Pasinetti, 1977, p. 120), which implies the indeterminacy of the price system. In other words, some outside and non-economic factors are necessary to determine the wage share/rate, and then the commodity prices. In contrast to the principle of marginal productivity, the factor income distribution cannot be determined solely by the demand-supply mechanism: for instance, institutional collective bargaining may be needed to determine the factor income distribution. This is a significant implication of the classical-Sraffian analysis, emphasized by those who favor Sraffa or those who are critical of the neoclassical demandsupply theory, such as Harcourt (1972, p. 201) and Nell (1967).

As already mentioned, there has been much debate on the assumption of constant returns to scale in Sraffa's model. Sraffian economists assert that it does not need to be assumed. Moreover, according to Roncaglia (2009, p. 50), Sraffa interpreted his own model as a photograph of the system at an instant in time. In other words, Sraffa focused on the situation of a given economic system at a given moment in time. Since no change is considered in the model, there is no need to assume constant returns to scale. Eatwell (1977) argues that Sraffa's model is based on the classical economics tradition, and emphasized the striking difference in the analytical basis between classical and neoclassical economics. In the former case, he argued that the size and composition of the output, technique being used, and real wages are the data that determine the distribution of surplus, prices, and quantities of physical input and labor. In contrast, in the latter case, the preferences of individuals, initial endowments of commodities and/or factors of production, distribution of the initial endowments among individuals, and technology are the data, and all variables are determined by the interaction between supply and demand. Eatwell (1977) concludes that constant returns to scale is an unnecessary assumption, following the classical economics tradition. Furthermore, Pasinetti (1977, pp. 116-117) argues that no constant returns to scale needs to be assumed in Sraffa's model because the standard system (8) is an imaginary system used to define the standard ratio and the physical composition of the standard commodity. ${ }^{8}$ Garegnani (2007), which is the rejoinder to Samuelson (2007), also asserts the nonnecessity of assuming constant returns to scale in Sraffa's model.

\footnotetext{
${ }^{8}$ The standard commodity, like the standard system, is an "anxiliary construction" (Sraffa, 1960, p. 31). Therefore, the wage rate in terms of the standard commodity does not mean, as Pasinetti (1977, p. 116) argues, that it is necessarily spent in the same proportion as the standard commodity. Burmeister (1968, 1977, 1984) and Samuelson (1987) misunderstand that the standard commodity is a consumption basket and, thus, underestimated its relevance, criticizing that the consumption basket is determined without any reference to individual preferences.
} 
In contrast, neoclassical economists assert that constant returns to scale are assumed explicitly. For example, according to Burmeister (1975), "one may deny constant returns to scale, but it is crucial then to determine what economically meaningful propositions remain valid;" Burmeister (1977) further states that "constant returns to scale is irrelevant for Sraffa's analysis only if one is content to pose irrelevant questions." He argues that the changes in the size and composition of output cannot be treated without assuming constant returns to scale in Sraffa's model. Then, if it is assumed, then fixing a factor income distribution, the changes in the size and composition of output have no effect on the choice of technique, as the nonsubstitution theorem shows. Otherwise, the changes in the size and composition of output generally affect the choice of technique. As a result, if the cost-minimizing technique changes, the standard commodity constructed from the present technique would no longer serve as an invariable measure of value, because the change in technical choice would vary the coefficient matrix $A$, which would lead to a corresponding change in the physical composition of the standard commodity and the standard ratio $\Pi$. Moreover, the linear distributional relation (10) derived from the current standard ratio would no longer hold. Therefore, he asserts that Sraffa's analysis is entirely irrelevant without assuming constant returns to scale. ${ }^{9}$

Although our main concern does not lie in the debate itself, we make one further comment here. If we allow a change in the factor income distribution, as Sraffa did, in order to examine the function of the standard commodity as an invariable measure of value, this may affect the choice of technique whenever multiple alternative techniques are available. Thus, for the same reason given in Burmeister (1977), discussed above, this may cause a shift from one technique $(A, L)$ to another $\left(A^{\prime}, L^{\prime}\right)$, which means the standard commodity derived from $(A, L)$ can no longer serve as the invariable measure of value. A critical point here is not the lack of constant returns to scale, unlike the neoclassical criticism of Sraffa, but the availability of multiple alternative techniques in a given economic system at a given moment in time. No economic school denies this feature. However, the above-mentioned debate indicates that, in the context of invariable measures of value, none of the neoclassical and Sraffian scholars seriously considered this feature, and consequently, the possibility of a changing in the costminimizing technique due to a change in the factor income distribution. ${ }^{10}$ Consequently, this suggests that the existence of an invariable measure of value in an economy with multiple alternative techniques is still an open question. We will discuss this problem in the next section.

\footnotetext{
${ }^{9}$ In addition, while Sraffa (1960, p. 26) regards the transformation from the actual economic system to the standard system (8) as an imaginary experiment, Samuelson (2000) argues that the transformation is impossible without assuming constant returns to scale.

${ }^{10}$ Note that the change in the cost-minimizing technique considered here is not related to any type of technical progress nor technological innovation, which is formulated as a variable set of available alternative techniques in a dynamic model of the economic system.
} 


\section{An Invariable Measure of Value in General Convex Economies}

In order to examine the existence of an invariable measure of value in an economy with multiple alternative techniques, we first propose the notion of a specific composite commodity, constructed from a general convex economy with non-increasing returns to scale. The basic idea of our proposal is that, given a set of alternative production techniques, which are fixed in a given economic system at a given moment in time, we construct a specific composite commodity using data of the complete set of alternative techniques, rather than using the data of a present cost-minimizing technique. The production of such a composite commodity is feasible in this option set, but is not necessarily producible by the present cost-minimizing technique. Indeed, the composite commodity is defined independently of the alternative techniques chosen from the overall option set.

We name this composite commodity a standard commodity, because it can be regarded as a mathematical extension of Sraffa's (1960) own standard commodity. In the following subsections, we show that our standard commodity can serve as an invariable measure of value in the sense of Ricardo (1951A).

\subsection{A standard commodity in general convex economies}

To represent an economy with multiple alternative techniques, we introduce a production possibility set, $P$, with non-increasing returns to scale. Here, $P$ is a set of available production processes (or techniques). A production process is defined as $\alpha \equiv\left(-\alpha_{l},-\underline{\alpha}, \bar{\alpha}\right)$, where $\alpha_{l}$ is a non-negative effective labor input of the process, $\underline{\alpha}$ is a non-negative vector of the inputs of the produced goods used in the process, and $\bar{\alpha}$ is a non-negative vector of the outputs of the $n$ goods. Denote the corresponding net output vector by $\widehat{\alpha} \equiv \bar{\alpha}-\underline{\alpha}$. There are small, mild restrictions on the properties of $P$ : (i) not activating any available production processes is feasible; (ii) to produce any non-negative vector of the $n$ goods as a net output, there is at least one production process available in $P$; (iii) to produce any non-negative and non-zero vector of commodities, the inputs of labor and at least one type of capital good are indispensable; and (iv) if there are two production processes available in $P$, any proportion, say $t \in(0,1)$, of one of the processes and the remaining proportion, $1-t$, of the other process can be jointly activated. A production possibility set $P$ satisfying these restrictions is so general that various types of technologies, such as Leontief production models, with or without technical choices, joint production models, and even neoclassical differentiable production functions can be analyzed here. ${ }^{11}$ Note also that there is no restriction that $P$ must represent a technology with constant returns to scale. Therefore, the following argument can be applied to a class of economies where there is a fixed endowment of a primary factor, such as land, other than labor.

For a production possibility set $P$, denote $\partial P \equiv\left\{\alpha \in P \mid \nexists \alpha^{\prime} \in P: \alpha^{\prime}>\alpha\right\}$, which is the set of efficient production processes in $P$. For each $\alpha \in P$, let $\Pi_{i} \equiv \frac{\bar{\alpha}_{i}}{\underline{\alpha}_{i}}-1$ for any commodity $i=1, \ldots, n$. We are then ready to define a specific composite commodity in each production

\footnotetext{
${ }^{11} \mathrm{~A}$ rigorous formulation of production possibility sets is given in Appendix A.
} 
set $P$, as follows.

Definition 1: For any production set, $P$, an $n$-dimensional positive vector, $y^{*}>\mathbf{0}$, is called a standard commodity if there exists a vector $\alpha^{*} \in \partial P$ with $\widehat{\alpha}^{*}=y^{*}$ and $\alpha_{l}^{*}=1$ satisfying the following properties: (i) $\Pi_{i}^{*}=\Pi_{j}^{*}$ for any $i, j=1, \ldots, n$; (ii) there is no other $\alpha^{\prime} \in P$ with $\alpha_{l}^{\prime}=1$ such that $\min _{i=1, \ldots, n} \Pi_{i}^{\prime}>\min _{i=1, \ldots, n} \Pi_{i}^{*}$; and (iii) $\widehat{\alpha}^{\prime \prime} \ngtr \widehat{\alpha}^{*}$ holds for any $\alpha^{\prime \prime} \in P$ with $\alpha_{l}^{\prime \prime}=1$ and $\min _{i=1, \ldots, n} \Pi_{i}^{\prime \prime}=\min _{i=1, \ldots, n} \Pi_{i}^{*}$. Correspondingly, the ratio $\Pi^{*} \equiv \min _{i=1, \ldots, n} \Pi_{i}^{*}$ is called the standard ratio, while the efficient production activity vector $\alpha^{*}$ is called the standard process.

This definition is well defined in that the standard commodity given by Definition 1 exists. ${ }^{12}$

Definition 1 implies that an $n$-dimensional positive vector, $y^{*}$, is called a standard commodity if it can be produced as the net product of an efficient production process $\alpha^{*}=$ $\left(-1,-x^{*}, x^{*}+y^{*}\right) \in \partial P$, with labor input $\alpha_{l}^{*}=1$, physical inputs $\underline{\alpha}^{*}=x^{*}$, and gross outputs $\bar{\alpha}^{*}=x^{*}+y^{*}$. In addition, under this process, the ratio of net product to physical inputs is uniform, $\frac{y_{i}^{*}}{x_{i}^{*}}=\frac{y_{j}^{*}}{x_{j}^{*}}$ for any $i, j=1, \ldots, n$. Moreover, this ratio is maximal among all production processes available in $P$, as specified in condition (ii) of Definition 1. Finally, although there may still be many positive commodity bundles satisfying conditions (i) and (ii) of Definition 1, the standard commodity $y^{*}$ is maximal among those bundles, as specified in condition (iii). This implies that $\alpha^{*}$ is the most capital intensive of the alternative processes satisfying (i) and (ii) of Definition $1 .^{13}$

If the production possibility set is represented by a Leontief production technique $(A, L),{ }^{14}$ then our standard commodity $y^{*}$ is identical to the Sraffian standard commodity $(I-A) b$, and our standard ratio, $\Pi^{*} \equiv \Pi_{i}^{*}=\Pi_{j}^{*}$ for any $i, j=1, \ldots, n$, is identical to the Sraffian standard ratio $\Pi$ discussed in section 2 . Therefore, Definition 1 is a mathematical extension of the Sraffian definition of the standard commodity presented in section 2 to an economy with a general production set, $P$. Correspondingly, the standard process $\alpha^{*}$ can be regarded as a generalization of the Sraffian standard system (8) to the production set $P$.

Some components of Definition 1 need further explanations. First, in the original standard system (8), the condition $L b=1$ is just a matter of normalization with no effect on the composition of $b$. In contrast, in Definition 1, where the constant returns to scale are not necessarily assumed, a choice of normalization, $\alpha_{l}^{*}=1$, would affect the composition of the standard commodity. However, none of the main results in this paper depend on such a specific choice of normalization, and the basic features of the standard commodity are invariant. Therefore, the choice of the one unit of labor as the normalization is a simple extension of the standard system to economies with non-constant returns to scale.

\footnotetext{
${ }^{12}$ The existence of the standard commodity is shown in Theorem A1 of Appendix B. The unique existence of the standard commodity is not necessarily guaranteed, though the standard ratio uniquely exists. If production set $P$ satisfies a "indecomposability" (Fujimoto, 1979, 1980) condition, the unique existence of the standard commodity can be shown, according to the non-linear Frobenius theorem (Fujimoto, 1979, 1980).

${ }^{13}$ Condition (iii) is satisfied trivially in an economy with a simple Leontief production technique, because there is no room for technical choice in such an economy.

${ }^{14}$ Note that the following production possibility set represents a Leontief production technique $(A, L)$ : $P_{(A, L)} \equiv\left\{\alpha \in \mathbb{R}_{-} \times \mathbb{R}_{-}^{n} \times \mathbb{R}_{+}^{n} \mid \exists x \in \mathbb{R}_{+}^{n}: \alpha \leqq(-L x,-A x, x)\right\}$.
} 
Second, Definition 1(i)-(ii) represents all of the basic characteristics of the Sraffian standard commodity. In contrast, Definition 1(iii) simply stipulates a specific selection rule, which we will apply to multiple commodity bundles satisfying Definition 1(i)-(ii), and so none of the main results in this paper depend on it. Because Definition 1(iii) becomes redundant whenever the uniqueness of such a commodity bundle is ensured, it represents a specific extension of the notion of the standard commodity to economies where the uniqueness of the standard system is not ensured.

As we mentioned at the beginning of this section, the standard commodity of Definition 1 is independent of which production process is a cost-minimizer in equilibrium. This is a distinctive feature of Definition 1, and is not observed in the case of Sraffa's own standard commodity.

To see this point, assume that the production possibility set $P$ is generated from a finite number of alternative Leontief production techniques, $\left\{\left(A^{k}, L^{k}\right)\right\} .{ }^{15}$ According to the Sraffian methodology, such as in Eatwell (1977), assuming that one Leontief technique, say $\left(A^{1}, L^{1}\right)$, is chosen as a cost-minimizer in the present equilibrium, it provides the data from which the standard commodity $y^{1}$ is constructed. Therefore, if the cost-minimizing technique changes to a different Leontief technique, say $\left(A^{2}, L^{2}\right)$; then, the standard commodity should also be transformed to $y^{2}$, constructed from the data of $\left(A^{2}, L^{2}\right)$. In contrast, the standard commodity $y^{*}$ of Definition 1 is constructed from the data of $P$, and it is therefore invariant with respect to such a technical change. Moreover, the standard ratio, $\Pi^{*}$, corresponding to $y^{*}$, should satisfy $\Pi^{*} \geqq \max _{k}\left\{\Pi^{k}\right\}$, where $\Pi^{k}$ is the standard ratio of technique $\left(A^{k}, L^{k}\right)$. For simplicity, let us consider the case where the standard process $\alpha^{*} \in P$ corresponding to $\Pi^{*}$ is uniquely specified and is activated by selecting a technique $\left(A^{*}, L^{*}\right) \in\left\{\left(A^{k}, L^{k}\right)\right\} .{ }^{16}$ Then, the linear equation $\pi=\Pi^{*}(1-\omega)$ dominates any other linear equation $\pi=\Pi^{k}(1-\omega)$, although this does not imply that $\left(A^{*}, L^{*}\right)$ is always cost-minimizing. ${ }^{17}$

We can present the argument above using the following simple, numerical example.

Example 1: Let there be two Leontief production techniques $\left(A^{1}, L^{1}\right)=\left(\left[\mathbf{a}_{1}^{1}, \mathbf{a}_{2}^{1}\right],\left(L_{1}^{1}, L_{2}^{1}\right)\right)$ with $\mathbf{a}_{1}^{1} \equiv\left[\begin{array}{c}\frac{1}{10} \\ \frac{1}{5}\end{array}\right], \mathbf{a}_{2}^{1} \equiv\left[\begin{array}{c}\frac{1}{10} \\ \frac{1}{10}\end{array}\right]$, and $\left(L_{1}^{1}, L_{2}^{1}\right) \equiv\left(1, \frac{4}{5}\right) ;$ and $\left(A^{2}, L^{2}\right)=\left(\left[\mathbf{a}_{1}^{2}, \mathbf{a}_{2}^{2}\right],\left(L_{1}^{2}, L_{2}^{2}\right)\right)$ with $\mathbf{a}_{1}^{2} \equiv\left[\begin{array}{c}\frac{5}{12} \\ \frac{1}{5}\end{array}\right], \mathbf{a}_{2}^{2} \equiv\left[\begin{array}{c}\frac{1}{10} \\ \frac{1}{12}\end{array}\right]$, and $\left(L_{1}^{2}, L_{2}^{2}\right) \equiv\left(\frac{3}{7}, \frac{4}{7}\right)$. Then, the production possibility set $P$ is given by

$$
P=\left\{\alpha \in \mathbb{R}_{-} \times \mathbb{R}_{-}^{2} \times \mathbb{R}_{+}^{2} \mid \exists x \in \mathbb{R}_{+}^{4}: \alpha \leqq\left(-\left(L_{1}^{1}, L_{2}^{1}, L_{1}^{2}, L_{2}^{2}\right) x,-\left[\mathbf{a}_{1}^{1}, \mathbf{a}_{2}^{1}, \mathbf{a}_{1}^{2}, \mathbf{a}_{2}^{2}\right] x,\left[I^{(2)}, I^{(2)}\right] x\right)\right\}
$$

\footnotetext{
${ }^{15}$ We can construct this as follows: for each $\left(A^{k}, L^{k}\right)$, the corresponding production set $P_{\left(A^{k}, L^{k}\right)}$ is specified as in footnote 14. Then, let $P$ be the convex hull of $\cup_{k} P_{\left(A^{k}, L^{k}\right)}$.

${ }^{16}$ That is, there exists $\widehat{x} \in \mathbb{R}_{++}^{n}$ such that $\alpha^{*}=\left(-L^{*} \widehat{x},-A^{*} \widehat{x}, \widehat{x}\right), L^{*} \widehat{x}=1$, and $y^{*}=\widehat{x}-A^{*} \widehat{x}$.

${ }^{17}$ This is because $\left(A^{*}, L^{*}\right)$ is not necessarily the solution to

$$
\min _{\left\{\left(A^{k}, L^{k}\right)\right\}} L^{k}\left(I-A^{k}\right)^{-1} c,
$$

where $c \geq \mathbf{0}$ is a real wage bundle. If $\left(A^{*}, L^{*}\right) \notin \arg \min _{\left\{\left(A^{k}, L^{k}\right)\right\}} L^{k}\left(I-A^{k}\right)^{-1} c$, then there is a technique that can be a cost-minimizer when the profit rate is sufficiently close to zero.
} 
where $I^{(2)} \equiv\left[\begin{array}{ll}1 & 0 \\ 0 & 1\end{array}\right]$. Let $\left(A^{12}, L^{12}\right) \equiv\left(\left[\mathbf{a}_{1}^{1}, \mathbf{a}_{2}^{2}\right],\left(L_{1}^{1}, L_{2}^{2}\right)\right)$ and $\left(A^{21}, L^{21}\right) \equiv\left(\left[\mathbf{a}_{1}^{2}, \mathbf{a}_{2}^{1}\right],\left(L_{1}^{2}, L_{2}^{1}\right)\right)$. Technique $\left(A^{12}, L^{12}\right)$ implies that the process of technique 1 is used to produce good 1 and that of technique 2 used to produce good 2 and technique $\left(A^{21}, L^{21}\right)$ implies that the process of technique 2 is used to produce good 1 and that of technique 1 is used to produce good 2 . These two techniques can be available as the definition of $P$ makes any mixture of $\left(A^{1}, L^{1}\right)$ and $\left(A^{2}, L^{2}\right)$ available.

Then, for each of $A^{1}, A^{2}, A^{12}$, and $A^{21}$, the corresponding Frobenius eigenvalues are respectively $\theta^{1}=0.241, \theta^{2}=0.469, \theta^{12}=0.233$, and $\theta^{21}=0.471$. Let $\Pi^{1} \equiv \frac{1}{\theta^{1}}-1$, so $\Pi^{1}=3.142$. Likewise, $\Pi^{2} \equiv \frac{1}{\theta^{2}}-1$, so $\Pi^{2}=1.134 ; \Pi^{12} \equiv \frac{1}{\theta^{12}}-1$, so $\Pi^{12}=3.286$; and $\Pi^{21} \equiv \frac{1}{\theta^{21}}-1$, so $\Pi^{21}=1.125$. Therefore, the standard ratio based on Definition 1 is $\Pi^{*} \equiv \max \left[\Pi^{1}, \Pi^{2}, \Pi^{12}, \Pi^{21}\right]=\Pi^{12}$. Then, the corresponding technique $\left(A^{*}, L^{*}\right)$ is $\left(A^{*}, L^{*}\right) \equiv$ $\left(A^{12}, L^{12}\right)$. Note that the Frobenius eigenvector associated with $A^{*}$ is $x^{*}=\left(\begin{array}{c}0.568 \\ 0.757\end{array}\right)$, which satisfies $L^{12} x^{*}=1$. Therefore, the standard commodity based on Definition 1 is then $y^{*}=\left(I^{(2)}-A^{*}\right) x^{*}=\left(\begin{array}{c}0.435 \\ 0.580\end{array}\right)$.

Given that $c=\left(\begin{array}{l}1 \\ 2\end{array}\right)$ is the real wage bundle which is also chosen as the numéraire, the wage-profit curves for each Leontief production techniques $\left(A^{k}, L^{k}\right)$ for $k=1,2,12$, and 21 , are defined as:

$$
w^{k}(\pi)=\frac{1}{L^{k}\left[I-(1+\pi) A^{k}\right]^{-1} c} .
$$

Then, the wage-profit frontier is defined by $w(\pi) \equiv \max \left\{w^{1}(\pi), w^{2}(\pi), w^{12}(\pi), w^{21}(\pi)\right\}$ for each $\pi \in\left[0, \Pi^{*}\right]$. Figure 1 depicts the wage-profit frontier in this economy.

\section{Insert Figure 1 here.}

The above shows that technique $\left(A^{*}, L^{*}\right)$ is not always utilized; technique $\left(A^{2}, L^{2}\right)$ is chosen in the present equilibrium with $\pi \in[0,0.291) .{ }^{18}$ Notwithstanding, the standard commodity $y^{*}$ is invariant, whichever technique is utilized.

Observing this feature, Sraffians may criticize Definition 1 because it allows the construction of the standard commodity based on production techniques that are not actually used, though they exist, and so are potentially useful in the present economy. However, there is no intrinsic reason why it should not be constructed from the data of existing but currently unused production techniques. ${ }^{19}$ Moreover, the data of the existing but currently unused production techniques would be relevant when considering the possibility of technical changes.

\footnotetext{
${ }^{18}$ Note that $\pi=0.291$ is the intersection of the wage-profit curves with respect to $\left(A^{2}, L^{2}\right)$ and $\left(A^{*}, L^{*}\right)$.

${ }^{19}$ In this respect, recall that the standard system (8) in Sraffa (1960) was imaginary in nature, and was only introduced to define the standard commodity and the standard ratio, as Pasinetti (1977, pp. 116-117) points out, but there is no intrinsic reason to require that a commodity serving as an invariable measure of value not be constructed from an imaginary system.
} 
Indeed, such an extended data set would be indispensable for generalizing the Sraffian standard commodity if the generalization is required to function as an invariable measure of value, even though a change in the factor income distribution involves a change of cost-minimizing technique. Indeed, returning to the above example of $\left\{\left(A^{k}, L^{k}\right)\right\}$, neither $y^{1}$ nor $y^{2}$ can serve as an invariable measure of value (in terms of Baldone (2006)) whenever a factor income redistribution (4) induces a change in the used technique. In contrast, $y^{*}$ can serve as an invariable measure of value in such case, as the next subsection shows.

\subsection{The invariable measure of value and the linear relation of the factor income distribution}

This section examines whether the standard commodity defined in Definition 1 can function as an invariable measure of value in economy $P$.

Consider a price system, $(p, w)$, which is a non-negative and non-zero vector with $p \neq \mathbf{0}$. Let there be a maximal rate of profit, $\pi \geqq 0$, and a production process, $\alpha=\left(-\alpha_{l},-\underline{\alpha}, \bar{\alpha}\right)$, on $P$ associated with $(p, w)$, such that

$$
\begin{aligned}
p \bar{\alpha} & =(1+\pi) p \underline{\alpha}+w \alpha_{l} \text { and } \\
p \bar{\alpha}^{\prime} & \leqq(1+\pi) p \underline{\alpha}^{\prime}+w \alpha_{l}^{\prime}
\end{aligned}
$$

hold for any $\alpha^{\prime}=\left(-\alpha_{l}^{\prime},-\underline{\alpha}^{\prime}, \bar{\alpha}^{\prime}\right)$ on $P .{ }^{20}$ Then, let us call such a price system an equilibrium price. $^{21}$ Consider a situation in which an equilibrium price changes from $(p, w)$ to $\left(p^{\prime}, w^{\prime}\right)$. Moreover, let $\pi$ (resp. $\pi^{\prime}$ ) be the maximal rate of profit associated with the price system, $(p, w)$ resp. $\left.\left(p^{\prime}, w^{\prime}\right)\right)$. Then, let $\triangle p \equiv p^{\prime}-p, \triangle w \equiv w^{\prime}-w$, and $\triangle \pi \equiv \pi^{\prime}-\pi$. Then, the following definitions are a generalization of the invariable measure of value, based on Baldone (2006):

Definition 2: Given a production set, $P$, let $(p, w)$ and $\left(p^{\prime}, w^{\prime}\right)$ be two different equilibrium prices, and $\pi$ and $\pi^{\prime}$ be their respective maximal profit rates. Then, a commodity bundle, $y>\mathbf{0}$, serves as an invariable measure of value with respect to a change from $(p, w)$ to $\left(p^{\prime}, w^{\prime}\right)$ if and only if there exist a non-negative and non-zero vector, $x$, and a positive number, $k>0$, such that the process $(-k,-x, x+y)$ is feasible for $P,(-k,-x, x+y) \in P$, and $\triangle p y=0$ holds whenever this price change involves a redistribution between profit and wages, (i.e., $\triangle \pi p x+\triangle w k=0)$.

\footnotetext{
${ }^{20}$ The maximal rate of profits exists, given the assumptions on the production set $P$ specified in the Appendix A.

${ }^{21}$ Note that this concept is consistent with the "price" in Sraffa (1960). It is true that Sraffa purposefully avoided using the term "equilibrium." According to Roncaglia (2009, pp. 121-122), the equality of the rate of profit in Sraffa's system implies that the mobility of capital between sectors, in the search for maximum profitability, would ultimately bring out a tendency for the rates of profit to converge towards this benchmark position. The uniform rate of profit in Sraffa's system does not require the equality of demand and supply, in contrast to the concept of "equilibrium" used by "marginalists." Roncaglia also asserted that it is only in this sense that one can speak of an "equilibrium" price within Sraffa's system. Our concept of an "equilibrium price" also only requires achieving the maximum rate of profit in all activated "sectors" under a production process $\alpha$.
} 
Definition 3: Given a production set, $P$, a commodity bundle, $y>\mathbf{0}$, serves as an invariable measure of value if and only if for any different equilibrium price systems $(p, w)$ and $\left(p^{\prime}, w^{\prime}\right)$, it serves as the invariable measure of value with respect to the change from $(p, w)$ to $\left(p^{\prime}, w^{\prime}\right)$.

That is, a commodity bundle serves as an invariable measure of value if and only if for any change in the price system involving a redistribution of profit and wages, the price of this commodity bundle is invariable. The definitions faithfully follow that of Sraffa reviewed in Section 2. More precisely, let us consider the counterfactual situation of a change in the factor income distribution from $(\pi, w)$ to $\left(\pi^{\prime}, w^{\prime}\right)$, while keeping the commodity price vector $p$ constant, such that the increase (resp. decrease) in profit is equal to the decrease (resp. increase) in the wage in the production process $(-k,-x, x+y)$ of the targeted commodity bundle, $y$. Such a change may be derived from a purely political conflict on the factor income distribution between capital and labor, or it may involve a change in technique. However, whatever the cause, it results in a change in commodity prices from $p$ to $p^{\prime}$. Then, the commodity bundle $y$ can serve as an invariable measure of value with respect to the change from $(p, w)$ to $\left(p^{\prime}, w^{\prime}\right)$ whenever $p y=p^{\prime} y$. Furthermore, if the commodity bundle satisfies such an invariable property for any change in price systems, with its corresponding redistribution between wage and profit, it can serve as an invariable measure of value.

It is worth emphasizing that, in the above definitions, the invariable property must hold, regardless of the cause of such a price change. For instance, even if the price change associated with the corresponding redistribution is generated by a technical change, so that the selected production process is changed in equilibrium, ${ }^{22}$ the value of the commodity bundle is required to be invariable.

It is quite interesting that, as in the following theorem, the standard commodity serves as an invariable measure of value in general convex economies.

Theorem 1: For every production set $P$, the standard commodity $y^{*}$ serves as an invariable measure of value.

Proof: See the Appendix A.

To show Theorem 1, first, note that for each price system $(p, w)$, the value of the standard commodity is given by $p y^{*}=\pi p x^{*}+w-\delta p x^{*}$, where $\pi$ is the maximal profit rate associated with the price system $(p, w)$ at $P$, and $\delta \geqq 0$ represents the shortfall of the profit rate from the maximal level generated by operating the standard process, $\alpha^{*}=\left(-1,-x^{*}, x^{*}+y^{*}\right)$, at the equilibrium price. Therefore, if $\alpha^{*}$ is a profit rate maximizer in the equilibrium price system $(p, w)$, then $\delta=0$ holds; otherwise, $\delta>0$ holds. In a similar way, the value of the standard commodity at another equilibrium price $\left(p^{\prime}, w^{\prime}\right)$ is given by $p^{\prime} y^{*}=\pi^{\prime} p^{\prime} x^{*}+w^{\prime}-\delta^{\prime} p^{\prime} x^{*}$. Then, as shown in detail in the Appendix, the standard commodity can serve as an invariable measure of value with respect to a change from $(p, w)$ to $\left(p^{\prime}, w^{\prime}\right)$ if and only if the shortfall of the profit rate generated by operating the standard system does not vary, $\delta=\delta^{\prime}$, corresponding to such a change of prices. It then follows that the standard commodity can serve as an invariable measure of value if and only if the shortfall in profit generated by operating the

\footnotetext{
${ }^{22}$ Such a situation is not relevant when we assume a single-product system, as in Baldone (2006).
} 
standard system is invariable with respect to any change in equilibrium prices involving an income redistribution. Moreover, it can be shown that a change in equilibrium prices involves an income redistribution, $\triangle \pi p x^{*}+\triangle w=0$, if and only if the shortfall in profit generated by operating the standard system does not vary corresponding to this price change, $\triangle \delta=0$. Therefore, we can conclude that for any price change, $\triangle p y^{*}=0$ holds whenever it involves $\triangle \pi p x^{*}+\triangle w=0$. Thus, the standard commodity serves as an invariable measure of value.

Let us now assume that the standard commodity, $y^{*}$, is selected as the numéraire, and define the set of price systems measured by the standard commodity as $\Delta^{y^{*}} \equiv\left\{(p, w) \in \mathbb{R}_{+}^{n+1} \mid p y^{*}=\right.$ $1\}$. Then, by definition, any non-negative and non-zero price vector, $p$, is normalized as $p y^{*}=1$. Given such a situation, we need to examine whether and under what condition the linear distributional relationship between profit and wage is preserved in the production set $P$. The following theorem is our second main result.

Theorem 2: Given a production set, $P$, let $\alpha^{*}=\left(-1,-x^{*}, x^{*}+y^{*}\right)$ be the standard process and $\Pi^{*}$ be the standard ratio. Then, the linear functional relation of factor income distribution $\pi^{\prime}=\Pi^{*}\left(1-w^{\prime}\right)$ holds for every equilibrium price system $\left(p^{\prime}, w^{\prime}\right) \in \Delta^{y^{*}}$ associated with the maximal profit rate, $\pi^{\prime}$, if and only if $p^{\prime} y^{*}=\pi^{\prime} p^{\prime} x^{*}+w^{\prime}$ holds for every equilibrium price system $\left(p^{\prime}, w^{\prime}\right)$ associated with $\pi^{\prime}$.

Proof: See the Appendix A.

The crucial point for the above analysis is whether the standard process $\alpha^{*}=\left(-1,-x^{*}, x^{*}+y^{*}\right)$ is a profit rate maximizer at all equilibrium prices available in $P$. If the condition $p^{\prime} y^{*}=$ $\pi^{\prime} p^{\prime} x^{*}+w^{\prime}$ holds for any equilibrium price system $\left(p^{\prime}, w^{\prime}\right)$ associated with $\pi^{\prime}$, then this implies that there is no shortfall in profit, $\delta^{\prime}=0$, in the standard process, for any equilibrium price vector $\left(p^{\prime}, w^{\prime}\right)$. This property is trivially satisfied in single-product systems, such as Leontief production economies and Sraffa (1960). In contrast, a general convex economy $P$ allows for the possibility of joint production and technical choices, in which the standard process may not be a profit rate maximizer at some equilibrium prices. In such a case, Theorem 2 suggests that the linearity of the factor income distribution no longer holds, in general.

To see this point, recall Example 1 that supposes the alternative Leontief production techniques $\left\{\left(A^{k}, L^{k}\right)\right\}$ for $k=1,2,12$, and 21. In the example, the standard ratio $\Pi^{*}$ is generated from technique $\left(A^{*}, L^{*}\right)$, and the linear equation $\pi=\Pi^{*}(1-\omega)$ dominates any other linear equation $\pi=\Pi^{k}(1-\omega)$ because $\Pi^{*}>\Pi^{k}$ for $k=1,2$, and 21. However, whenever the technique $\left(A^{*}, L^{*}\right)$ is not a cost-minimizer at some equilibrium prices $\left(p^{\prime}, w^{\prime}\right)$ with the rate of profit $\pi^{\prime} \in[0,0.291)$, this implies that $p^{\prime} x^{*}<\left(1+\pi^{\prime}\right) p^{\prime} A^{*} x^{*}+w^{\prime}$ for the Frobenius vector $x^{*}>\mathbf{0}$ of $\left(A^{*}, L^{*}\right)$, with $L^{*} x^{*}=1$. In this case, by taking $y^{*}=\left(I-A^{*}\right) x^{*}$ as the numéraire, we have $\pi^{\prime}>\Pi^{*}\left(1-w^{\prime}\right)$. Thus, the linear functional relation of the factor income distribution does not hold for this equilibrium price system $\left(p^{\prime}, w^{\prime}\right) \in \Delta^{y^{*}}$.

Recall that an implication of the linear distributional relation (10) was that the determination of the factor income distribution can be formulated independently of competitive mechanisms in commodity markets under an economy with a simple Leontief production technique. However, the general impossibility of the linear distributional relation shown by Theorem 2 does not necessarily imply that this indeterminacy no longer occurs under an economy with a more general production technology than the simple Leontief one. Here, the 
linear distributional relation is just a sufficient condition warranting the Sraffian indeterminacy (Mandler, 1999, p. 699). Therefore, in terms of the indeterminacy, we should not be distressed by the impossibility of the linear distributional relation.

\section{Concluding Remarks}

In this study, we examine the invariable measure of value in general convex economies by proposing an extension of Sraffa's standard commodity to such economies. Following Baldone (2006), we focus on the invariance of a measure of value when the price changes induced by the income redistribution between profit and wage, as shown by (4), take place. Theorem 1 demonstrates the general possibility of the price invariance of the extended standard commodity in general convex economies, which implies that the extended standard commodity serves as the invariable measure of value with respect to the income redistribution, even though it involves a change in technique. Thus, we can ascertain how the income redistribution and the induced technical change would affect price movements in commodity markets, independently of the numéraire effect problem.

Furthermore, we examine whether the linear distributional relation is valid in the general convex economies. Theorem 2 demonstrates that, unlike in Sraffa's model, the linear distributional relation is not preserved in general, even though the standard commodity is adopted as the numéraire. It is preserved if and only if the standard process $\alpha^{*}$ is a profit maximizer at all equilibrium prices. Put another way, the linear distributional relation is preserved in the general convex economies if and only if the standard commodity can be produced without incurring a shortfall of profit at all equilibrium prices. This condition is always satisfied in the Leontief-Sraffa model, but is not always satisfied in general convex economies.

General convex economies are similar to the economic environment where Ricardo originally attempted to find the invariable measure of value, in that the economies allow for changes in both the factor income distribution and technique. Our contribution is that we have shown the existence of an invariable measure of value that follows Ricardo's original attempt as faithfully as possible. Moreover, that we are able to treat joint production without the difficulty found in Sraffa (1960), which Manara (1980) and Schefold (1989) both confronted, is a novel characteristic of our model.

There remain two open questions with regard to the Ricardian invariable measure of value. Firstly, we have presumed an economy with a fixed general convex set of available production techniques. This means that we do not address the issues of technical progress or technological innovation, although Ricardo obviously gave attention to their effects on the overall economy. ${ }^{23}$ In order to discuss these issues, we must consider a further generalization of the standard commodity to an economy with a variable set of available production techniques, and then examine its performance as an invariable measure of value in such an economy. This feature may create a conceptual difficulty in the construction of the standard commodity because we have to rationally expect, in the present period, the intertemporal path of technical progress that would occur in future; otherwise, it is impossible to construct a generalized standard commodity as an invariable measure of value in such an economy.

\footnotetext{
${ }^{23}$ See, in particular, Ricardo (1951A, chap. 31).
} 
However, it should, in general, be impossible to have a perfectly rational expectation about future technological innovation. We leave this fundamental question for future research.

Secondly, we argued that the proposed generalized standard commodity can function as the invariable measure of value under an economy with technology exhibiting non-increasing returns to scale, because the production possibility set is presumed to be convex only. Thus, we do not consider the case of an economy with technology that exhibits increasing returns to scale. Note that the existence of the generalized standard commodity is warranted, even in such an economy, whenever the production possibility set has the property of being homogeneous of degree $k$, with $k>1 .^{24}$ However, to examine the performance of such a generalized standard commodity as an invariable measure of value, we have to discuss what constitutes an equilibrium price system in such an economy. This is because the notion of equilibrium price systems associated with the maximal profit rates is not well defined in such an economy, owing to the non-convexity of the production possibility set. There are several alternative notions of equilibrium prices in an economy with increasing return to scale technology, such as marginal cost pricing. The performance of the generalized standard commodity as an invariable measure of value may depend on which of these alternative notions is selected in such an economy. This interesting question is also left for future research.

\section{Appendix A: Mathematical Formulation of Production Possibility Set and Proofs of Theorems}

Here, we rigorously formulate our model presented in Section 3.

Let $\mathbb{R}_{+}$be the set of all non-negative real numbers, and $\mathbb{R}_{++}$be the set of all positive numbers. Let $\mathbb{R}_{+}^{n}$ (resp. $\mathbb{R}_{++}^{n}$ ) be the $n$-fold Cartesian product of $\mathbb{R}_{+}$(resp. $\left.\mathbb{R}_{++}\right)$. For any $x, y \in \mathbb{R}_{+}^{n}$, we write $x \geqq y$ to mean $\left[x_{i} \geqq y_{i}\right.$, for all $\left.i=1, \ldots, n\right], x \geq y$ to mean $\left[x_{i} \geqq y_{i}\right.$, for all $i=1, \ldots, n$ and $x \neq y]$, and $x>y$ to mean $\left[x_{i}>y_{i}\right.$, for all $\left.i=1, \ldots, n\right]$.

Let there be $n$ reproducible commodities. Let $\mathbf{0}$ denote the null vector. The production technology is represented by a production set, $P$, which has elements of the form $\alpha=$ $\left(-\alpha_{l},-\underline{\alpha}, \bar{\alpha}\right)$, where $\alpha_{l} \in \mathbb{R}_{+}$is the effective labor input of the process; $\underline{\alpha} \in \mathbb{R}_{+}^{n}$ are the inputs of the produced goods used in the process; and $\bar{\alpha} \in \mathbb{R}_{+}^{n}$ are the outputs of the $n$ goods. Thus, elements of $P$ are vectors in $\mathbb{R}^{2 n+1}$. Then, the following assumptions are imposed on production set $P$.

Assumption 0 (A0). $P$ is closed and convex in $\mathbb{R}^{2 n+1}$ and $\mathbf{0} \in P$.

Assumption 1 (A1). For all $\alpha \in P$, if $\bar{\alpha} \geq \mathbf{0}$, then $\alpha_{l}>0$ and $\underline{\alpha} \geq \mathbf{0}$.

Assumption 2 (A2). For all $c \in \mathbb{R}_{+}^{n}$, there is an $\alpha \in P$ such that $\widehat{\alpha} \equiv \bar{\alpha}-\underline{\alpha} \geqq c{ }^{25}$

\footnotetext{
${ }^{24}$ The production possibility set $P$ is homogeneous of degree $k$ if there exists $k \in \mathbb{R}_{++}$, with $k>1$, such that for all $\alpha \in P$, and for any $\lambda>0,\left(-\lambda \alpha_{l},-\lambda \underline{\alpha}, \lambda^{k} \bar{\alpha}\right) \in P$.

${ }^{25} \mathbf{A 2}$ is standard in economic models with convex production sets, like Roemer (1980, 1982), Flaschel (1983), and Yoshihara (2010). It is a generalization of the productiveness presumed in the standard Leontief production models.
} 
Under $\mathbf{A} \mathbf{0}^{\sim} \mathbf{A} \mathbf{2}$, the following lemma can be expressed and proven rigorously, as follows.

Lemma 1: For any production set $P$ satisfying $\boldsymbol{A} \boldsymbol{O}^{\sim} \boldsymbol{A} \mathcal{2}$, the standard commodity $y^{*}$ associated with the standard system $\alpha^{*}=\left(-1,-x^{*}, x^{*}+y^{*}\right) \in \partial P$ serves as an invariable measure of value if and only if for any equilibrium prices $(p, w)$ and $\left(p^{\prime}, w^{\prime}\right)$ such that $\triangle \pi p x^{*}+\triangle w=0$, there exist non-negative numbers $\delta, \delta^{\prime} \geqq 0$ such that $p y^{*}=\pi p x^{*}+w-\delta p x^{*}, p^{\prime} y^{*}=$ $\pi^{\prime} p^{\prime} x^{*}+w^{\prime}-\delta^{\prime} p^{\prime} x^{*}$, and $\delta=\delta^{\prime}$ hold.

Proof: Consider any equilibrium prices $(p, w)$ and $\left(p^{\prime}, w^{\prime}\right)$ such that $p \neq \mathbf{0} \neq p^{\prime}$ and $\triangle \pi p x^{*}+$ $\triangle w=0$. By Definition 1, $y^{*}=\Pi x^{*}$ holds for some $\Pi>0$. Since $\alpha_{l}^{*}=1, p y^{*} \leqq \pi p x^{*}+w$ and $p^{\prime} y^{*} \leqq \pi^{\prime} p^{\prime} x^{*}+w^{\prime}$ hold, in general. Therefore, there are non-negative numbers $\delta, \delta^{\prime} \geqq 0$ such that $p y^{*}=\pi p x^{*}+w-\delta p x^{*}$ and $p^{\prime} y^{*}=\pi^{\prime} p^{\prime} x^{*}+w^{\prime}-\delta^{\prime} p^{\prime} x^{*}$ hold. Then,

$$
\begin{aligned}
\triangle p y^{*} & =(\pi+\triangle \pi) \triangle p x^{*}+\left(\triangle \pi p x^{*}+\triangle w\right)-\left(\delta^{\prime} p^{\prime} x^{*}-\delta p x^{*}\right) \\
& =(\pi+\triangle \pi) \triangle p x^{*}+\left(\triangle \pi p x^{*}+\triangle w\right)-(\delta+\triangle \delta) \triangle p x^{*}-\triangle \delta p x^{*},(\text { a. } 1)
\end{aligned}
$$

where $\triangle \delta \equiv \delta^{\prime}-\delta$. Since $y^{*}=\Pi x^{*}$, equation (a.1) can be reduced to

$$
\triangle p y^{*}=\frac{1}{\Pi}((\pi+\triangle \pi)-(\delta+\triangle \delta)) \triangle p y^{*}+\left(\triangle \pi p x^{*}+\triangle w\right)-\triangle \delta p x^{*}
$$

Thus, unless $\frac{1}{\Pi}\left(\pi^{\prime}-\delta^{\prime}\right)=1$, we have

$$
\triangle p y^{*}=\left[1-\frac{1}{\Pi}\left(\pi^{\prime}-\delta^{\prime}\right)\right]^{-1}\left(\left(\triangle \pi p x^{*}+\triangle w\right)-\triangle \delta p x^{*}\right) .
$$

Suppose that $y^{*}$ serves as an invariable measure of value with respect to a change from $(p, w)$ to $\left(p^{\prime}, w^{\prime}\right)$. Then, by Definition $2, \triangle \pi p x^{*}+\triangle w=0$ implies $\triangle p y^{*}=0$. Then, by equation (a.2), $\triangle \delta p x^{*}=0$ must hold. Since $x^{*}>\mathbf{0}$ by Definition 2 and $y^{*}=\Pi x^{*}, p x^{*}>0$ holds, and so $\triangle \delta=0$ must hold. Therefore, $\delta=\delta^{\prime}$ holds.

Conversely, let there be $\delta, \delta^{\prime} \in \mathbb{R}_{+}$such that $p y^{*}=\pi p x^{*}+w-\delta p x^{*}, p^{\prime} y^{*}=\pi^{\prime} p^{\prime} x^{*}+$ $w^{\prime}-\delta^{\prime} p^{\prime} x^{*}$, and $\delta=\delta^{\prime}$ hold. Because we consider a redistribution of wages and profit, $\triangle \pi \neq 0 \neq \triangle w$ holds. Therefore, $\left(\pi^{\prime}-\delta^{\prime}\right) \neq(\pi-\delta)$ holds. Then, at least one of $\left(\pi^{\prime}-\delta^{\prime}\right)$ and $(\pi-\delta)$ is not equal to $\Pi$. Thus, without loss of generality, let $\left(\pi^{\prime}-\delta^{\prime}\right) \neq \Pi$. Then, equation (a.3) implies that $\triangle p y^{*}=0$ follows from $\triangle \pi p x^{*}+\triangle w=0$. Thus, by Definition 2 , $y^{*}$ serves as an invariable measure of value with respect to a change from $(p, w)$ to $\left(p^{\prime}, w^{\prime}\right)$. Because $(p, w)$ and $\left(p^{\prime}, w^{\prime}\right)$ are any equilibrium prices, $y^{*}$ serves as an invariable measure of value, by Definition 3 .

By letting $P(p, w) \equiv\left\{\alpha \in P \mid \alpha=\arg \max _{\alpha^{\prime}} \frac{p{\overline{\alpha^{\prime}}}^{\prime}-p \underline{\alpha}^{\prime}-w \alpha_{l}^{\prime}}{p \underline{\alpha}^{\prime}}\right\}$, Corollary 1 can be obtained as follows.

Corollary 1. Under any production set, $P$, satisfying $\boldsymbol{A} \boldsymbol{O}^{\sim} \boldsymbol{A} \mathscr{2}$, take any equilibrium prices $(p, w)$ and $\left(p^{\prime}, w^{\prime}\right)$ such that $\alpha^{*} \in P(p, w) \cap P\left(p^{\prime}, w^{\prime}\right)$ holds. Then, the standard commodity $y^{*}$ serves as an invariable measure of value with respect to a change from $(p, w)$ to $\left(p^{\prime}, w^{\prime}\right)$. 
Proof. Note that $\alpha^{*}=\left(-1,-x^{*}, x^{*}+y^{*}\right) \in P(p, w) \cap P\left(p^{\prime}, w^{\prime}\right)$ implies that $p y^{*}=\pi p x^{*}+$ $w-\delta p x^{*}$ and $p^{\prime} y^{*}=\pi^{\prime} p^{\prime} x^{*}+w^{\prime}-\delta^{\prime} p^{\prime} x^{*}$ hold for $\delta=0=\delta^{\prime}$. Then, by Lemma 1 , the desired result immediately follows.

Given a price vector $(p, w) \in \mathbb{R}_{+}^{n+1}$, let $\omega \equiv \frac{w}{p y^{*}}$, which is the labor share measured by the standard commodity. Then, we have the following lemma.

Lemma 2: Given $P$ satisfying $\boldsymbol{A O}^{\sim} \boldsymbol{A}$ 2, the linear functional relation of the factor income distribution, $\pi^{\prime}=\Pi\left(1-\omega^{\prime}\right)$, holds for any equilibrium price system $\left(p^{\prime}, w^{\prime}\right) \in \mathbb{R}_{+}^{n+1}$ associated with the maximal profit rate $\pi^{\prime}$ if and only if $p^{\prime} y^{*}=\pi^{\prime} p^{\prime} x^{*}+w^{\prime}$ holds for any equilibrium price system $\left(p^{\prime}, w^{\prime}\right) \in \mathbb{R}_{+}^{n+1}$ associated with $\pi^{\prime}$.

Proof. By the definition of an equilibrium price system $\left(p^{\prime}, w^{\prime}\right) \in \mathbb{R}_{+}^{n+1}$ associated with the maximal profit rate $\pi^{\prime}$, it is generally true that $p^{\prime} y^{*}=\pi^{\prime} p^{\prime} x^{*}+w^{\prime}-\delta^{\prime} p^{\prime} x^{*}$ for some $\delta^{\prime} \geqq 0$. Then, because $y^{*}=\Pi x^{*}$ holds for some $\Pi>0$, it follows that $\Pi p^{\prime} x^{*}=p^{\prime} y^{*}$ and, thus, $1=\frac{1}{\Pi} \pi^{\prime}+\frac{w^{\prime}}{p^{\prime} y^{*}}-\frac{1}{\Pi} \delta^{\prime}$. The last equation implies that $\pi^{\prime}=\Pi\left(1-\omega^{\prime}\right)+\delta^{\prime}$. Thus, we have a functional relation $\pi^{\prime}=\Pi\left(1-\omega^{\prime}\right)+\delta\left(p^{\prime}, w^{\prime}\right)$ for any equilibrium price system $\left(p^{\prime}, w^{\prime}\right) \in \mathbb{R}_{+}^{n+1}$, where $\delta\left(p^{\prime}, w^{\prime}\right)$ represents a non-negative, real-value function $\delta: \mathbb{R}_{+}^{n+1} \rightarrow \mathbb{R}_{+}$ such that for any $\left(p^{\prime}, w^{\prime}\right) \in \mathbb{R}_{+}^{n+1}, \delta\left(p^{\prime}, w^{\prime}\right)=0$ holds if and only if $\alpha^{*} \in P\left(p^{\prime}, w^{\prime}\right)$. As a result of this functional relation, for any equilibrium price system $\left(p^{\prime}, w^{\prime}\right) \in \mathbb{R}_{+}^{n+1}, \pi^{\prime}=\Pi\left(1-\omega^{\prime}\right)$ holds if and only if $\delta\left(p^{\prime}, w^{\prime}\right)=0$. Therefore, $\pi^{\prime}=\Pi\left(1-\omega^{\prime}\right)$ holds for any equilibrium price $\left(p^{\prime}, w^{\prime}\right) \in \mathbb{R}_{+}^{n+1}$ if and only if $\alpha^{*} \in P\left(p^{\prime}, w^{\prime}\right)$ for any equilibrium price system $\left(p^{\prime}, w^{\prime}\right) \in \mathbb{R}_{+}^{n+1}$. Because $\alpha^{*} \in P\left(p^{\prime}, w^{\prime}\right)$ implies $p^{\prime} y^{*}=\pi^{\prime} p^{\prime} x^{*}+w^{\prime}$, we obtain the desired result.

Proof of Theorem 1. From the proof of Lemma 2, we have a functional relation of wages and profit rates such that $\frac{1}{\Pi} \pi+\omega=1+\frac{1}{\Pi} \delta(p, w)$ for any equilibrium price system $(p, w) \in \mathbb{R}_{+}^{n+1}$, where $\delta(p, w)=0$ holds if and only if $\alpha^{*} \in P(p, w)$. Consider a change in the wage and profit rates from $(\pi, w)$ to $\left(\pi^{\prime}, w^{\prime}\right)$, while keeping the commodity prices so as to satisfy $\triangle \pi p x^{*}+\triangle w=0$. In general, a change in the wage and profit rates from $(\pi, w)$ to $\left(\pi^{\prime}, w^{\prime}\right)$ is given by the following rule:

$$
\begin{aligned}
\triangle \pi & =\pi^{\prime}-\pi=\Pi\left(1-\omega^{\prime}\right)-\Pi(1-\omega)+\left(\delta^{\prime}-\delta\right) \\
& =-\Pi \triangle \omega+\triangle \delta
\end{aligned}
$$

Thus, a change in the wage and profit rates is represented by $\frac{1}{\Pi} \triangle \pi+\triangle \omega=\frac{1}{\Pi} \triangle \delta$, in general. Thus, $\frac{1}{\Pi} \triangle \pi+\triangle \omega=0$ if and only if $\triangle \delta=0$. Furthermore, if a change in the wage and profit rates from $(\pi, w)$ to $\left(\pi^{\prime}, w^{\prime}\right)$, while maintaining the commodity prices, satisfies $\triangle \pi p x^{*}+\triangle w=$ 0 , this implies that $\frac{1}{\Pi} \triangle \pi+\frac{\Delta w}{p y^{*}}=0 \Rightarrow \frac{1}{\Pi} \triangle \pi+\triangle \omega=0$. Thus, $\triangle \delta=0$ holds.

Let us take any equilibrium prices, $(p, w),\left(p^{\prime}, w^{\prime}\right) \in \mathbb{R}_{+}^{n+1}$, with $p \neq \mathbf{0} \neq p^{\prime}$ associated with the maximal profit rates $\pi \geqq 0$ and $\pi^{\prime} \geqq 0$, respectively. If $\alpha^{*} \in P(p, w) \cap P\left(p^{\prime}, w^{\prime}\right)$, then $y^{*}$ serves as an invariable measure of value with respect to a change from $(p, w)$ to $\left(p^{\prime}, w^{\prime}\right)$, as shown by Corollary 1 .

Suppose that $\alpha^{*} \in P(p, w) \backslash P\left(p^{\prime}, w^{\prime}\right)$. Then, because $p y^{*}=\pi p x^{*}+w$ and $p^{\prime} y^{*}=$ $\pi^{\prime} p^{\prime} x^{*}+w^{\prime}-\delta^{\prime} p^{\prime} x^{*}$ with $\delta^{\prime}>0, \triangle \delta \neq 0$ holds. Therefore, $\triangle \pi p x^{*}+\triangle w \neq 0$ holds. Thus, by Definition $2, y^{*}$ trivially serves as an invariable measure of value with respect to a change 
from $(p, w)$ to $\left(p^{\prime}, w^{\prime}\right)$. Note that the same argument can be applied to the case where $\alpha^{*} \in P\left(p^{\prime}, w^{\prime}\right) \backslash P(p, w)$.

Suppose that $\alpha^{*} \notin P(p, w) \cup P\left(p^{\prime}, w^{\prime}\right)$. Then, $p y^{*}=\pi p x^{*}+w-\delta p x^{*}$ and $p^{\prime} y^{*}=$ $\pi^{\prime} p^{\prime} x^{*}+w^{\prime}-\delta^{\prime} p^{\prime} x^{*}$, for some $\delta, \delta^{\prime}>0$. If $\delta \neq \delta^{\prime}$, then $\triangle \pi p x^{*}+\triangle w \neq 0$ holds from $\triangle \delta \neq 0$. Thus, by Definition $2, y^{*}$ trivially serves as an invariable measure of value with respect to a change from $(p, w)$ to $\left(p^{\prime}, w^{\prime}\right)$. Let $\delta=\delta^{\prime}$. Then, $\triangle \delta=0$. Thus, whenever a change from $(p, w)$ to $\left(p^{\prime}, w^{\prime}\right)$ secures $\triangle \pi p x^{*}+\triangle w=0, y^{*}$ serves as an invariable measure of value with respect to a change from $(p, w)$ to $\left(p^{\prime}, w^{\prime}\right)$, by Definition 2 and Lemma 1.

In summary, for any equilibrium prices $(p, w),\left(p^{\prime}, w^{\prime}\right) \in \mathbb{R}_{+}^{n+1}$, with $p \neq \mathbf{0} \neq p^{\prime}, y^{*}$ serves as an invariable measure of value with respect to a change from $(p, w)$ to $\left(p^{\prime}, w^{\prime}\right)$. Thus, by Definition $3, y^{*}$ serves as an invariable measure of value.

Proof of Theorem 2. By Lemma $2, \pi^{\prime}=\Pi\left(1-\omega^{\prime}\right)$ for any equilibrium price system $\left(p^{\prime}, w^{\prime}\right) \in \mathbb{R}_{+}^{n+1}$ associated with the maximal profit rate $\pi^{\prime}$ if and only if $p^{\prime} y^{*}=\pi^{\prime} p^{\prime} x^{*}+w^{\prime}$ holds for any equilibrium price system $\left(p^{\prime}, w^{\prime}\right) \in \mathbb{R}_{+}^{n+1}$ associated with $\pi^{\prime}$. Let any equilibrium price system $\left(p^{\prime}, w^{\prime}\right)$ be normalized by the simplex $\Delta^{y^{*}}$. Then, $\omega^{\prime}$ is reduced to $w^{\prime}$. Thus, $\pi^{\prime}=\Pi\left(1-w^{\prime}\right)$ for any equilibrium price system $\left(p^{\prime}, w^{\prime}\right) \in \Delta^{y^{*}}$ associated with the maximal profit rate $\pi^{\prime}$ if and only if $p^{\prime} y^{*}=\pi^{\prime} p^{\prime} x^{*}+w^{\prime}$ holds for any equilibrium price system $\left(p^{\prime}, w^{\prime}\right) \in$ $\Delta^{y^{*}}$ associated with $\pi^{\prime}$.

\section{Appendix B: The Existence of the Standard Commodity}

To provide a general existence of the standard commodity, we first introduce the following additional assumptions on the production set.

Assumption 3 (A3). For all $\alpha \in P$, and for all $\left(-\alpha_{l}^{\prime},-\underline{\alpha}^{\prime}, \bar{\alpha}^{\prime}\right) \in \mathbb{R}_{-} \times \mathbb{R}_{-}^{n} \times \mathbb{R}_{+}^{n}$, if $\left(-\alpha_{l}^{\prime},-\underline{\alpha}^{\prime}, \bar{\alpha}^{\prime}\right) \leqq \alpha$, then $\left(-\alpha_{l}^{\prime},-\underline{\alpha}^{\prime}, \bar{\alpha}^{\prime}\right) \in P$.

The model of production sets with $\mathbf{A 0}^{\sim} \mathbf{A} 3$ still covers a broad class of production technologies. Indeed, it still contains the class of von Neumann production models and the class of Leontief production models with the possibility of technical choices.

For each production possibility set $P$, given $k>0$, let $P\left(\alpha_{l}=k\right) \equiv\left\{\alpha \in P \mid \alpha_{l}=k\right\}$ and

$$
\partial P\left(\alpha_{l}=k\right) \equiv\left\{\alpha \in P\left(\alpha_{l}=k\right) \mid \nexists \alpha^{\prime} \in P\left(\alpha_{l}=k\right):\left(-\underline{\alpha}^{\prime}, \bar{\alpha}^{\prime}\right)>(-\underline{\alpha}, \bar{\alpha})\right\} .
$$

Given the above setup of the model and the definition of the standard commodity presented in Section 3, the general existence of the standard commodity is proven as follows.

Theorem A1: Under $\boldsymbol{A O}^{\sim} \boldsymbol{A}$ 3, there exists a standard commodity $y^{*} \in \mathbb{R}_{++}^{n}$ associated with $\alpha^{* * *} \in \partial P\left(\alpha_{l}=1\right)$ and $\widehat{\alpha}^{* * *}=y^{*}$.

Proof: Given $P\left(\alpha_{l}=1\right)$, which is convex, let $P_{\alpha_{l}=1}$ be the minimal closed convex cone containing $P\left(\alpha_{l}=1\right)$. By definition, $P_{\alpha_{l}=1}$ is a closed convex cone with $P_{\alpha_{l}=1}\left(\alpha_{l}=1\right)=$ $P\left(\alpha_{l}=1\right)$. If $P$ is a cone, $P_{\alpha_{l}=1}=P$. Given $P_{\alpha_{l}=1}$, let $\bar{P}_{\alpha_{l}=1} \equiv\left\{\alpha \in P_{\alpha_{l}=1} \mid \sum_{i=1, \ldots, n} \bar{\alpha}_{i}=1\right\}$. 
Let $F: P_{\alpha_{l}=1} \rightarrow \mathbb{R}_{+}$be such that for each $\alpha \in P_{\alpha_{l}=1}, F(\alpha)=\min _{i=1, \ldots, n} \frac{\bar{\alpha}_{i}}{\underline{\alpha}_{i}}$, where

$$
\frac{\bar{\alpha}_{i}}{\underline{\alpha}_{i}} \equiv\left\{\begin{array}{cc}
0 & \text { if } \bar{\alpha}_{i}=0 \\
+\infty & \text { if } \underline{\alpha}_{i}=0 \text { and } \bar{\alpha}_{i}>0 .
\end{array}\right.
$$

This mapping is continuous and well defined, by A1. Note that by $\mathbf{A 2}, \mathbf{A} 3$, and the convexity of $P$, there exists $\alpha^{\prime} \in \partial P\left(\alpha_{l}=1\right)$ such that $\widehat{\alpha}^{\prime}>\mathbf{0}$. Hence, for $\frac{\alpha^{\prime}}{\sum_{i=1, \ldots, n} \bar{\alpha}_{i}^{\prime}} \in \partial \bar{P}_{\alpha_{l}=1}$, $F\left(\frac{\alpha^{\prime}}{\sum_{i=1, \ldots, n} \bar{\alpha}_{i}^{\prime}}\right)>0$. This implies that $\sup _{\alpha \in \bar{P}_{\alpha_{l}=1}} F(\alpha)>0$. Suppose that $\sup _{\alpha \in \bar{P}_{\alpha_{l}=1}} F(\alpha)=$ $+\infty$. Then, there exists a sequence $\left\{\alpha^{k}\right\} \subseteq \bar{P}_{\alpha_{l}=1}$ such that $\alpha^{k} \rightarrow \alpha^{*}$ with $\lim _{k \rightarrow+\infty} F\left(\alpha^{k}\right)=$ $F\left(\alpha^{*}\right)=\sup _{\alpha \in \bar{P}_{\alpha_{l}=1}} F(\alpha)$. By the definition of $F, F\left(\alpha^{*}\right)=+\infty$ implies that $\alpha^{*}=\left(-l, \mathbf{0}, \bar{\alpha}^{*}\right)$ for some $l \geqq 0$ and some $\bar{\alpha}^{*}>\mathbf{0}$. Because $\bar{P}_{\alpha_{l}=1}$ is closed, $\alpha^{*} \in \bar{P}_{\alpha_{l}=1}$. By construction, $\bar{P}_{\alpha_{l}=1}$ satisfies A1, which is a contradiction of $\alpha^{*} \in \bar{P}_{\alpha_{l}=1}$. Thus, $\sup _{\alpha \in \bar{P}_{\alpha_{l}=1}} F(\alpha)<+\infty$. Then, $\sup _{\alpha \in \bar{P}_{\alpha_{l}=1}} F(\alpha)=\max _{\alpha \in \bar{P}_{\alpha_{l}=1}} F(\alpha)$. Let $\alpha^{*} \in \arg \max _{\alpha \in \bar{P}_{\alpha_{l}=1}} F(\alpha)$. Then, by the cone property, $\frac{\alpha^{*}}{\alpha_{l}^{*}} \in P\left(\alpha_{l}=1\right)$ and $\frac{\alpha^{*}}{\alpha_{l}^{*}} \in \arg \max _{\alpha \in P\left(\alpha_{l}=1\right)} F(\alpha)$. Hence, without loss of generality, let $\alpha^{*} \in \arg \max _{\alpha \in P\left(\alpha_{l}=1\right)} F(\alpha)$. Then, $\alpha^{*} \in \partial P\left(\alpha_{l}=1\right)$. Because there exists $\alpha^{\prime} \in \partial P\left(\alpha_{l}=1\right)$ such that $F\left(\alpha^{\prime}\right)>0, \max _{\alpha \in P\left(\alpha_{l}=1\right)} F(\alpha)>0$ holds, which implies that $\bar{\alpha}^{*}>\mathbf{0}$.

Define $V \equiv\left\{\bar{\alpha}-F\left(\alpha^{*}\right) \underline{\alpha} \mid(-1,-\underline{\alpha}, \bar{\alpha}) \in P\left(\alpha_{l}=1\right)\right\}$. Then, $V$ is a closed convex set with $V \cap \mathbb{R}_{++}^{n}=\varnothing$. Therefore, there exists $p^{*} \in \mathbb{R}_{+}^{n} \backslash\{\mathbf{0}\}$ such that $p^{*}\left[\bar{\alpha}-F\left(\alpha^{*}\right) \underline{\alpha}\right] \leqq 0$ for all $\alpha \in P\left(\alpha_{l}=1\right)$, and $p^{*} z>0$ for all $z \in \mathbb{R}_{++}^{n}$. This implies that if there exists $i \in\{1, \ldots, n\}$, with $\frac{\bar{\alpha}_{i}^{*}}{\underline{\alpha}_{i}^{*}}>F\left(\alpha^{*}\right)$, then $p_{i}^{*}=0$. By $p^{*} \in \mathbb{R}_{+}^{n} \backslash\{\mathbf{0}\}$, there exists $i \in\{1, \ldots, n\}$ with $\frac{\bar{\alpha}_{i}^{*}}{\underline{\alpha}_{i}^{*}}=F\left(\alpha^{*}\right)$ and $p_{i}^{*}>0$. Thus, $p^{*}\left[\bar{\alpha}^{*}-F\left(\alpha^{*}\right) \underline{\alpha}^{*}\right]=0$. Hence, $p^{*}$ is a supporting vector of $\alpha^{*} \in \partial P\left(\alpha_{l}=1\right)$. Let $\alpha^{* *} \in P\left(\alpha_{l}=1\right)$ be such that, for each $i \in\{1, \ldots, n\}$ with $\frac{\bar{\alpha}_{i}^{*}}{\underline{\alpha}_{i}^{*}}>F\left(\alpha^{*}\right),\left(\underline{\alpha}_{i}^{* *}, \bar{\alpha}_{i}^{* *}\right) \in \mathbb{R}_{++}^{2}$ with $\frac{\bar{\alpha}_{i}^{* *}}{\underline{\alpha}_{i}^{* *}} \equiv F\left(\alpha^{*}\right)$. (Note that such a construction is possible by A3.) Furthermore, for each $i \in\{1, \ldots, n\}$ with $\frac{\bar{\alpha}_{i}^{*}}{\underline{\alpha}_{i}^{*}}=F\left(\alpha^{*}\right),\left(\underline{\alpha}_{i}^{* *}, \bar{\alpha}_{i}^{* *}\right) \equiv\left(\underline{\alpha}_{i}^{*}, \bar{\alpha}_{i}^{*}\right)$. Then, by construction, $p^{*}\left[\bar{\alpha}^{* *}-F\left(\alpha^{*}\right) \underline{\alpha}^{* *}\right]=0$, which implies that $\alpha^{* *} \in \partial P\left(\alpha_{l}=1\right)$. Note that $\underline{\alpha}^{* *}>\mathbf{0}$ and $\bar{\alpha}^{* *}=F\left(\alpha^{*}\right) \underline{\alpha}^{* *}$.

Denote the set of such production processes as $\alpha^{* *}$ by $P(F)$. Then, for any $\alpha^{* *} \in P(F)$, $\alpha^{* *} \in \partial P\left(\alpha_{l}=1\right)$ and $F\left(\alpha^{* *}\right) \geqq F\left(\alpha^{\prime}\right)$ hold for all $\alpha^{\prime} \in P\left(\alpha_{l}=1\right)$. Because $P(F)$ is compact by $P(F) \subseteq \partial P\left(\alpha_{l}=1\right) \cap\{\alpha \in P \mid \widehat{\alpha}>\mathbf{0}\}$, there exists $\alpha^{* * *} \in P(F)$ such that for any $\alpha^{* *} \in P(F), \bar{\alpha}^{* * *}-\underline{\alpha}^{* * *} \nless \bar{\alpha}^{* *}-\underline{\alpha}^{* *}$.

Let $y^{*} \equiv \bar{\alpha}^{* * *}-\underline{\alpha}^{* * *}$. Recall that there exists $\alpha^{\prime} \in \partial P\left(\alpha_{l}=1\right)$ such that $\hat{\alpha}^{\prime}>\mathbf{0}$ and $F\left(\alpha^{\prime}\right)>0$, which implies $F\left(\alpha^{*}\right) \geqq F\left(\alpha^{\prime}\right)>1$. Therefore, $y^{*}>\mathbf{0}$. Then, there exists a positive number $\Pi>0$ such that $\Pi x^{*}=y^{*}$ for $x^{*} \equiv \underline{\alpha}^{* * *}>\mathbf{0}$. By Definition 1, $y^{*}>\mathbf{0}$ is a standard commodity of the production set $P$. Note that $1+\Pi=\max _{\alpha \in P\left(\alpha_{l}=1\right)} F(\alpha)=F\left(\alpha^{* *}\right)$ and $y^{*} \nless \bar{\alpha}^{* *}-\underline{\alpha}^{* *}$ for any $\alpha^{* *} \in P(F)$. This guarantees the uniqueness of the standard ratio $\Pi$ for $P$. 


\section{References}

Baldone, S. (2006) On Sraffa's standard commodity: Is its price invariant with respect to changes in income distribution? Cambridge Journal of Economics, 30, 313-319.

Bellino, E. (2004) On Sraffa's standard commodity, Cambridge Journal of Economics, 28, $121-132$.

Burmeister, E. (1968) On a theorem of Sraffa, Economica, 35, 83-87.

Burmeister, E. (1975) A comment on "This age of Leontief ... and who?" Journal of Economic Literature, 13, 454-457.

Burmeister, E. (1977) The irrelevance of Sraffa's analysis without constant returns to scale, Journal of Economic Literature, 15, 68-70.

Burmeister, E. (1980) Capital Theory and Dynamics, Cambridge University Press, Cambridge.

Burmeister, E. (1984) Sraffa, labor theories of value, and the economics of the real wage determination, Journal of Political Economy, 92, 508-526.

Eatwell, J. (1977) The irrelevance of returns to scale in Sraffa's analysis, Journal of Economic Literature, 15, 61-68.

Flaschel, P. (1983) Actual labor values in a general model of production, Econometrica, 51, 435-454.

Flaschel, P. (1986) Sraffa's standard commodity: No fulfillment of Ricardo's dream of an "invariable measure of value," Journal of Institutional and Theoretical Economics, 142, 588602 .

Fujimoto, T. (1979) Nonlinear generalization of the Frobenius theorem, Journal of Mathematical Economics, 6, 17-21.

Fujimoto, T. (1980) Addendum to nonlinear generalization of the Frobenius theorem, Journal of Mathematical Economics, 7, 213-214.

Garegnani, P. (1984) Value and distribution in the classical economists and Marx, Oxford Economic Papers, 36, 291-325.

Garegnani, P. (2007) Professor Samuelson on Sraffa and the classical economists, European Journal of the History of Economic Thought, 14, 181-242.

Harcourt, G. (1972) Some Cambridge Controversies in the Theory of Capital, Cambridge University Press, Cambridge.

Harcourt, G. (2003) The Structure of Post-Keynesian Economics: The Core Contributions of the Pioneers, Cambridge University Press, Cambridge.

Kurz, H. and Salvadori, N. (1987) Burmeister on Sraffa and the labor theory of value: A comment, Journal of Political Economy, 95, 870-881. 
Kurz, H. and Salvadori, N. (1993) The "standard commodity" and Ricardo's search for an "invariable measure of value," in Baranzini, M. and Harcourt, G. (eds.) The Dynamics of the Wealth of Nations, St. Martin's Press, New York, 95-123.

Kurz, H. and Salvadori, N. (2015) Invariable measure of value, in Kurz, H. and Salvadori, N. (eds.) The Elgar Companion to David Ricardo, Edward Elgar, Cheltenham, 205-211.

Manara, C. F. (1980) Sraffa's model for the joint production of commodities by means of commodities, in Pasinetti, L. (ed.) Essays on the Theory of Joint Production, Macmillan Press, Basingstoke, 1-15.

Mandler, M. (1999) Sraffian indeterminacy in general equilibrium, Review of Economic Studies, 66, 693-711.

Morishima, M. (1964) Equilibrium, Stability, and Growth: A Multi-sectoral Analysis, Clarendon Press, Oxford.

Nell, E. (1967) Theories of growth and theories of value, Economic Development and Cultural Change, 16, 15-26.

Pasinetti, L. (1977) Lectures on the Theory of Production, Columbia University Press, New York.

Pasinetti, L. (1981) Structural Change and Economic Growth: A Theoretical Essay on the Dynamics of the Wealth of Nations, Cambridge University Press, Cambridge.

Pasinetti, L. (1993) Structural Economic Dynamics: A Theory of the Economic Consequences of Human Learning, Cambridge University Press, Cambridge.

Ricardo, D. (1951A) On the Principles of Political Economy and Taxation, in Sraffa, P. (ed.) The Works and Correspondence of David Ricardo, vol. I, Cambridge University Press, Cambridge.

Ricardo, D. (1951B) Pamphlets and Papers 1809-1811, in Sraffa, P. (ed.) The Works and Correspondence of David Ricardo, vol. III, Cambridge University Press, Cambridge.

Roemer, J.E. (1980) A General Equilibrium Approach to Marxian Economics, Econometrica, $48,505-530$.

Roemer, J.E. (1982) A General Theory of Exploitation and Class, Harvard University Press, Cambridge (Mass.).

Roncaglia, A. (2009) Piero Sraffa, Palgrave Macmillan, Basingstoke.

Samuelson, P. (1987) Sraffian economics, in Eatwell, J., Milgate, M., and Newman, P. (eds.) The New Palgrave Dictionary of Economics, Vol. 4, Macmillan, London, 452-461.

Samuelson, P. (1990) Revisionist findings on Sraffa, in Bharadwaj, K. and Schefold, B. (eds.) Essays on Piero Sraffa, Unwin Hyman, London, 263-280.

Samuelson, P. (2000) Sraffa's hits and misses, in Kurz, H. (ed.) Critical Essays on Piero Sraffa's Legacy in Economics, Cambridge University Press, Cambridge, 111-152.

Samuelson, P. and Etula, E. (2006) Testing to confirm that Leontief-Sraffa matrix equations for input/output must obey constant returns to scale, Economics Letters, 90, 183-188. 
Schefold, B. (1989) Mr. Sraffa on Joint Production and Other Essays, London, Routledge.

Schefold, B. (1997) Normal Prices, Technical Change, and Accumulation, Macmillan Press, Basingstoke.

Sraffa, P. (1951) Introduction, in Sraffa, P. (ed.) The Works and Correspondence of David Ricardo, vol. I, Cambridge University Press, Cambridge, xiii-lxii.

Sraffa, P. (1960) Production of Commodities by Means of Commodities: Prelude to a Critique of Economic Theory, Cambridge University Press, Cambridge.

Solow, R. (2014) Comments on Scott Carter, Research in Political Economy, 29, 63-67.

Woods, J. (1990) The Production of Commodities: An Introduction to Sraffa, Macmillan Education, Basingstoke.

Yoshihara, N. (2010) Class and Exploitation in General Convex Cone Economies, Journal of Economic Behavior \& Organization, 75, 281-296. 


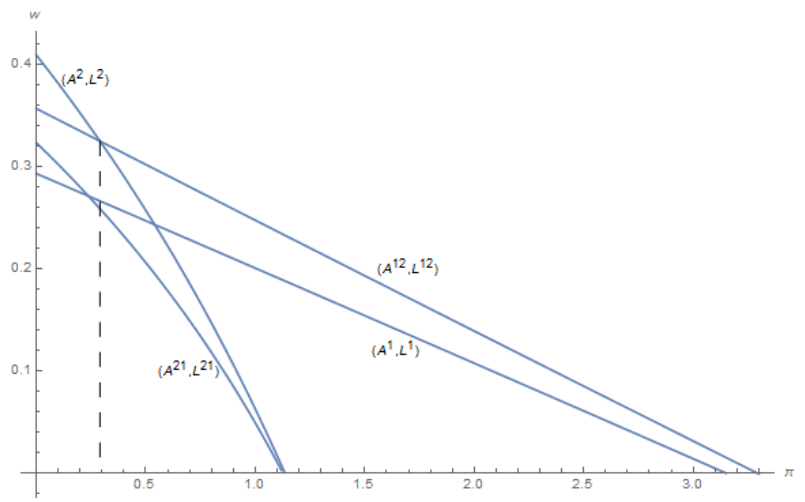

Figure 1: Wage-profit Frontier 